\title{
Nutraceutical management of male infertility-towards new generation therapeutics
}

\author{
Olabode Ekerin ${ }^{1 *}$, Calistus Okechukwu Kenechukwu²
}

\begin{abstract}
Infertility is one of the most significant public health-related concerns globally. Both male and female factors can cause it. Male factors include poor sperm quality, idiopathic oligospermia, asthenozoospermia, and isolated asthenozoospermia. Many substances, collectively known as nutraceuticals, have been studied for their capacity to enhance hormonal state and sperm parameters through different mechanisms. Nutraceuticals are components in dietary supplements prescribed to prevent or treat a wide range of diseases. This article aims to highlight certain nutrients that can help improve male fertility based on recent advancements in the management of male infertility.

Keywords: Nutraceutical, Infertility, Male, Asthenozoospermia, Dietary Supplements, Nigeria
\end{abstract}

\section{Background}

Infertility is defined as the inability to conceive after 12 months or more of regular unprotected intercourse. It is a significant public health challenge affecting 60-80 million couples worldwide [1]. Studies have also reported that male factor infertility accounts for more than $40 \%$ of infertility cases worldwide [2]. Male factors, such as poor sperm quality, are responsible for $25 \%$ of infertility cases [3]. Other causes include Idiopathic oligospermia (low sperm counts) [4,5], asthenozoospermia (absence of sperm motility) which is indicated in 19 percent of infertile cases[6], and isolated asthenozoospermia, which can be caused by sperm dysfunction, varicocele, infection, or genetic factors [7].

\section{Nutraceuticals}

In 1989, the word Nutraceutical was coined by Dr. Stephen DeFelice from "nutritional" and pharmaceutical. He defined it as food or part of food that aid the prevention and/or treatment of diseases and/or disorder[8]. This concept has gotten a lot of attention in recent years, especially in developed countries, as new therapeutic options that can improve patient health are being developed due to the current knowledge of unbalanced diets[9]. Different studies have also revealed that poor and homogenous diets caused by environmental variables such as air pollution, stress, toxins, and other hazardous compounds in

*Correspondence: bodeekerin@gmail.com

${ }^{1}$ Department of Paediatrics, Obafemi Awolowo University Teaching Hospitals Complex, Nigeria.

Full list of author information is available at the end of the article food may be the reason for the decrease in male sperm quality in the last 50 years [10-12]. This article aims to highlight certain nutrients that can help improve male fertility based on recent advancements in the management of male infertility.

\section{Myo-inositol}

Myo-inositol (MYO), a member of the vitamin B complex family, is the most common form in nature produced by the human body [13]. MYO is made from glucose-6-phosphate and excreted through the kidneys and is involved in different systemic activities and signaling pathways in the plasma membrane as a precursor of second messengers [14]. Sertoli cells that respond to follicle-stimulating hormone (FSH) are the major producers in the male reproductive system[9]. The Myoinositol content of the seminiferous tubule fluid is higher than that of the seminal plasma. A High concentration of Myoinositol is found in the epididymis, and its depletion has been related to decreased fertility [15]. Several human investigations [16-18] carried out have found a link between altered mitochondrial function (oxidative damage) and decreased motility and fertilization capacity of spermatozoa. Myo-inositol increases mitochondrial membrane potential and restores mitochondrial cristae morphology. It also has a role in various activities, including capacitation, acrosome response, and sperm motility control [19].

\section{L-arginine}

It is a basic natural amino acid with a high concentration in the nuclei of haploid cells and a 50\% concentration in the nuclei of spermatozoa. Exogenous L-arginine has been demonstrated in 
several studies[20] to have various positive pharmacological effects. It promotes the synthesis of nitric oxide, ensuring a sufficient oxygen supply to muscles that induce penile erections when stimulated at the level of the cavernous bodies of the penis or the anococcygeal muscles. Clinical findings reveal that oral administration of L-arginine to infertile men improves the total proportion of healthy spermatozoa and motility, resulting in successful pregnancies [21].

\section{L-carnitine}

In the epididymis and seminal fluid, L-carnitine is found in high concentrations. It is involved in the Beta-oxidation of longchain free fatty acids in mitochondria [22]. Low L carnitine levels in the mitochondria limit fatty acid synthesis, lowering energy generation and sperm motility [23,24]. L-carnitine supplementation improves seminal parameters, improving sperm quality and motility [25]. According to Italian research, a 6-month therapy with a mixture of L-carnitine and L-acetylcarnitine increased sperm motility, notably in males with asthenozoospermia [26]. A similar study [27] done one year later confirmed the same findings. It also revealed an improvement in the total oxyradical scavenging capacity of seminal fluid in males with idiopathic asthenozoospermia.

\section{Vitamin E}

It is an antioxidant that is found inside the cell membrane and thereby prevents free radical-induced damage. Vitamin E functions as a biological lipid peroxidation inhibitor. Malondialdehyde levels in spermatozoa are considerably reduced, and sperm motility is improved when vitamin $\mathrm{E}$ is taken orally[28]. Another study [29] indicated that vitamin E and selenium act together to improve sperm motility and sperm count.

\section{Selenium}

It is a trace element mainly found in cereals, fish, meat, poultry, and eggs. It is a component of selenoproteins, which are structural components of mature spermatozoa and are involved in testosterone metabolism. Sperm capsular selenoprotein, in the form of glutathione peroxidase, protects spermatozoa against peroxidation [30]. Selenium and/or glutathione deficiencies can result in mid-piece instability of the spermatozoa, leading to poor motility. In males with asthenoteratospermia or asthenospermia, a combination of selenium and vitamin $\mathrm{E}$ has been found to enhance sperm quality [31]. Selenium supplementation has been seen to enhance total sperm count, concentration, percentage of normal morphology, and motility in subfertile men [32].

\section{Folic acid}

Folic acid, also known as vitamin B9, is a small molecule. It aids cell growth and is required for the production of DNA, transfers RNA and proteins. Male infertility has been linked to a change in folic acid metabolism. A mouse model discovered that a paternal folate deficiency changes the mouse sperm epigenome, which has a detrimental influence on pregnancy outcomes [33]. Folic acid is important for treating low reproductive function and improving sperm quality. Folic acid and zinc were found to increase the concentration of spermatozoa and improve the morphology of the same in placebo-controlled research [34].

Zinc

Zinc is an important mineral with several biological roles. It plays an essential role in the organization of DNA, RNA, and proteins and the stability of cell membranes and cell division [35]. Zinc is a key component in the functioning of the male reproductive system. Zinc deficiency has been linked to male sterility and infertility, as it is required for spermatogenesis and testicular development [36]. Stress, cigarette smoke, pollution, and alcohol can reduce zinc levels, and zinc deficiency has also been related to low sperm counts and testosterone levels [37]. According to a recent meta-analysis [38], Infertile males had considerably lower seminal plasma zinc concentrations than normal controls. Following zinc treatment in infertile men, sperm volume, motility, and morphology all improved significantly.

\section{Conclusion}

This article supports previous findings that the impact of food in male factor infertility needs more investigation. It also implies that eating a healthy diet is a safe approach to increase at least one metric of sperm quality. Future studies should focus on improving our understanding of the impact of food and dietary chemicals on testicular metabolism and sperm production. Further research on the effect of food and/or dietary chemicals in sperm production and testicular cell metabolism might benefit from animal experiments. Furthermore, further clinical research is needed to determine the best dosage and treatment duration.

\section{Abbreviation \\ MYO - Myo-inositol}

\section{Declaration}

\section{acknowledgment}

The authors would like to express gratitude to participants who helped in filling the google form.

\section{Funding}

The authors received no financial support for their research, authorship, and/or publication of this article.

\section{Availability of data and materials}

Data will be available by emailing bodeekerin@gmail.com

\section{Authors' contributions}

Olabode Ekerin (OE) is the principal investigator of this manuscript (Viewpoint). OE is the responsible author for the study concept, design, writing, reviewing, editing, and approving the manuscript in its final form. Calistus Okechukwu Kenechukwu (COK) is involved in writing, reviewing, and editing this manuscript.

Ethics approval and consent to participate

We conducted the research following the Declaration of Helsinki. However, "Commentary Article" need no ethics committee approval. 
Consent for publication

Not applicable

Competing interest

The authors declare that they have no competing interest.

\section{Open Access}

This article is distributed under the terms of the Creative Commons Attribution 4.0 International License (http://creativecommons.org/licenses/by/4.0/), which permits unrestricted use, distribution, and reproduction in any medium, provided you give appropriate credit to the original author(s) and the source, provide a link to the Creative Commons license, and indicate if changes were made. The Creative Commons Public Domain Dedication waiver (http://creativecommons.org/publicdomain/zero/1.0/) applies to the data made available in this article, unless otherwise stated.

Author details

${ }^{1}$ Department of Paediatrics, Obafemi Awolowo University Teaching Hospitals Complex, Nigeria. bodeekerin@gmail.com ${ }^{2}$ Department of Internal medicine, Obafemi Awolowo University Teaching Hospitals Complex, Nigeria. calistus959@gmail.com

\section{Article Info}

Received: 13 July 2021

Accepted: 09 August 2021

Published: 19 August 2021

\section{References}

1. Ross C, Morriss A, Khairy M, Khalaf Y, Braude P, Coomarasamy A, El-Toukhy T. A systematic review of the effect of oral antioxidants on male infertility. Reprod Biomed Online. 2010 Jun;20(6):711-23. doi: 10.1016/j.rbmo.2010.03.008. Epub 2010 Mar 10. PMID: 20378409.

2. Eslamian G, Amirjannati N, Rashidkhani B, Sadeghi MR, Hekmatdoost A. Intake of food groups and idiopathic asthenozoospermia: a case-control study. Hum Reprod. 2012 Nov;27(11):3328-36. doi: 10.1093/humrep/des311. Epub 2012 Aug 30. PMID: 22940769.

3. Evers JL. Female subfertility. Lancet. 2002 Jul 13;360(9327):1519. doi: 10.1016/S0140-6736(02)09417-5. PMID: 12126838.

4. Hirsh A. Male subfertility. BMJ. 2003 Sep 20;327(7416):669-72. doi: 10.1136/bmj.327.7416.669. Erratum in: BMJ. 2003 Nov 15;327(7424):1165-a. PMID: 14500443; PMCID: PMC196399.

5. Ortega C, Verheyen G, Raick D, Camus M, Devroey P, Tournaye H. Absolute asthenozoospermia and ICSI: what are the options? Hum Reprod Update. 2011 Sep-Oct;17(5):684-92. doi: 10.1093/humupd/dmr018. Epub 2011 Aug 3. PMID: 21816768.

6. Curi SM, Ariagno JI, Chenlo PH, Mendeluk GR, Pugliese MN, Sardi Segovia LM, Repetto HE, Blanco AM. Asthenozoospermia: analysis of a large population. Arch Androl. 2003 SepOct;49(5):343-9. doi: 10.1080/01485010390219656. PMID: 12893510.

7. Luconi M, Forti G, Baldi E. Pathophysiology of sperm motility. Front Biosci. 2006 May 1;11:1433-47. doi: 10.2741/1894. PMID: 16368527.8 .

Kalra EK. Nutraceutical - Definition and introduction. AAPS PharmSci. 2003;5(3):1-2.
8. De Rose AF, Baldi M, Gallo F, Rossi P, Gattuccio I. The management of male infertility: from nutraceuticals to diagnostics. 1:1-8. IJMDAT 2018; 1 (1): e110

9. Vézina D, Mauffette F, Roberts KD, Bleau G. Selenium-vitamin E supplementation in infertile men. Effects on semen parameters and micronutrient levels and distribution. Biol Trace Elem Res. 1996 Summer;53(1-3):65-83. doi: 10.1007/BF02784546. PMID: 8862739 .

10. Salas-Huetos A, Bulló M, Salas-Salvadó J. Dietary patterns, foods and nutrients in male fertility parameters and fecundability: a systematic review of observational studies. Hum Reprod Update. 2017 Jul 1;23(4):371-389. doi: 10.1093/humupd/dmx006. PMID: 28333357.

11. Carlsen E, Giwercman A, Keiding N, Skakkebaek NE. Evidence for decreasing quality of semen during past 50 years. BMJ. 1992 Sep 12;305(6854):609-13. doi: 10.1136/bmj.305.6854.609. PMID: 1393072; PMCID: PMC1883354.

12. Condorelli RA, La Vignera S, Di Bari F, Unfer V, Calogero AE. Effects of myoinositol on sperm mitochondrial function in-vitro. Eur Rev Med Pharmacol Sci. 2011 Feb;15(2):129-34. PMID: 21434479.

13. Reaction Frank Eisenberg, Ranganathan Parthasarathy, Measurement of biosynthesis of myo-inositol from glucose 6phosphate, Methods in Enzymology, Academic Press, Volume 141, 1987, Pages 127-143, ISSN 0076-6879, ISBN 9780121820411, https://doi.org/10.1016/0076-6879(87)41061-6

14. Yeung, C.-H., Anapolski, M., Setiawan, I., Lang, F. and Cooper, T.G. (2004), Effects of Putative Epididymal Osmolytes on Sperm Volume Regulation of Fertile and Infertile c-ros Transgenic Mice. Journal of Andrology, 25: 216-223. https://doi.org/10.1002/j.1939-4640.2004.tb02781.x

15. Amaral S, Oliveira PJ, Ramalho-Santos J. Diabetes and the impairment of reproductive function: possible role of mitochondria and reactive oxygen species. Curr Diabetes Rev. 2008 Feb;4(1):46-54. doi: 10.2174/157339908783502398. PMID: 18220695.

16. Zorn B, Vidmar G, Meden-Vrtovec H. Seminal reactive oxygen species as predictors of fertilization, embryo quality and pregnancy rates after conventional in vitro fertilization and intracytoplasmic sperm injection. Int J Androl. 2003 Oct;26(5):279-85. doi: 10.1046/j.1365-2605.2003.00424.x. PMID: 14511216.

17. Hammadeh ME, Radwan M, Al-Hasani S, Micu R, Rosenbaum P, Lorenz M, Schmidt W. Comparison of reactive oxygen species concentration in seminal plasma and semen parameters in partners of pregnant and non-pregnant patients after IVF/ICSI. Reprod Biomed Online. 2006 Nov;13(5):696-706. doi: 10.1016/s14726483(10)60661-x. PMID: 17169183

18. Facchinetti F, Bizzarri M, Benvenga S, D'Anna R, Lanzone A, Soulage C, Di Renzo GC, Hod M, Cavalli P, Chiu TT, Kamenov ZA, Bevilacqua A, Carlomagno G, Gerli S, Oliva MM, Devroey P. Results from the International Consensus Conference on Myoinositol and d-chiro-inositol in Obstetrics and Gynecology: the link between metabolic syndrome and PCOS. Eur J Obstet Gynecol Reprod Biol. 2015 Dec;195:72-6. doi: 10.1016/j.ejogrb.2015.09.024. Epub 2015 Oct 3. PMID: 26479434.

19. Mohamed Z. Gad, Anti-aging effects of 1-arginine, Journal of Advanced Research, Volume 1, Issue 3, 2010, Pages 169-177, ISSN 2090-1232, https://doi.org/10.1016/j.jare.2010.05.001. 
20. Wu, G., Bazer, F.W., Davis, T.A. et al. Arginine metabolism and nutrition in growth, health and disease. Amino Acids 37, 153-168 (2009). https://doi.org/10.1007/s00726-008-0210-y

21. Jeulin C, Lewin LM. Role of free L-carnitine and acetyl-Lcarnitine in post-gonadal maturation of mammalian spermatozoa. Hum Reprod Update. 1996 Mar-Apr;2(2):87-102. doi: 10.1093/humupd/2.2.87. PMID: 9079406.

22. Izzo PL, Olivieri L, Bartelloni M. Free L-carnitine in human semen : its variability in different andrologic pathologies. Fertil Steril [Internet]. 1984;42(2):263-7. Available from: http://dx.doi.org/10.1016/S0015-0282(16)48024-6

23. Sinclair S. Male infertility: nutritional and environmental considerations. Altern Med Rev. 2000 Feb;5(1):28-38. PMID: 10696117.

24. Ahmed SD, Karira KA, Jagdesh, Ahsan S. Role of L-carnitine in male infertility. J Pak Med Assoc. 2011 Aug;61(8):732-6. PMID: 22355991.

25. Lenzi A, Sgrò P, Salacone P, Paoli D, Gilio B, Lombardo F, Santulli M, Agarwal A, Gandini L. A placebo-controlled doubleblind randomized trial of the use of combined 1-carnitine and 1acetyl-carnitine treatment in men with asthenozoospermia. Fertil Steril. 2004 Jun;81(6):1578-84. doi: 10.1016/j.fertnstert.2003.10.034. PMID: 15193480 .

26. Balercia G, Regoli F, Armeni T, Koverech A, Mantero F, Boscaro M. Placebo-controlled double-blind randomized trial on the use of L-carnitine, L-acetylcarnitine, or combined L-carnitine and Lacetylcarnitine in men with idiopathic asthenozoospermia. Fertil Steril. 2005 Sep;84(3):662-71. doi: 10.1016/j.fertnstert.2005.03.064. PMID: 16169400.

27. Suleiman SA, Ali ME, Zaki ZM, el-Malik EM, Nasr MA. Lipid peroxidation and human sperm motility: protective role of vitamin E. J Androl. 1996 Sep-Oct;17(5):530-7. PMID: 8957697.

28. Vézina D, Mauffette F, Roberts KD, Bleau G. Selenium-vitamin E supplementation in infertile men. Effects on semen parameters and micronutrient levels and distribution. Biol Trace Elem Res. 1996 Summer;53(1-3):65-83. doi: 10.1007/BF02784546. PMID: 8862739 .

29. Surai PF, Blesbois E, Grasseau I, Chalah T, Brillard J, Wishart GJ. Fatty acid composition, glutathione peroxidase and superoxide dismutase activity and total antioxidant activity of avian semen. 1998;120:527-33.

30. Moslemi MK, Tavanbakhsh S. Selenium-vitamin E supplementation in infertile men: effects on semen parameters and pregnancy rate. Int J Gen Med. 2011 Jan 23;4:99-104. doi: 10.2147/JJGM.S16275. PMID: 21403799; PMCID: PMC3048346.

31. Safarinejad MR, Safarinejad S. Efficacy of Selenium and / or NAcetyl-Cysteine for Improving Semen Parameters in Infertile Men : A Double-Blind, Placebo Controlled, Randomized Study. JURO [Internet]. 2009;181(2):741-51. Available from: http://dx.doi.org/10.1016/j.juro.2008.10.015

32. Lambrot R, Xu C, Saint-Phar S, Chountalos G, Cohen T, Paquet M, Suderman M, Hallett M, Kimmins S. Low paternal dietary folate alters the mouse sperm epigenome and is associated with negative pregnancy outcomes. Nat Commun. 2013;4:2889. doi: 10.1038/ncomms3889. PMID: 24326934; PMCID: PMC3863903.

33. Wong WY, Merkus HM, Thomas CM, Menkveld R, Zielhuis GA, Steegers-Theunissen RP. Effects of folic acid and zinc sulfate on male factor subfertility: a double-blind, randomized, placebo- controlled trial. Fertil Steril. 2002 Mar;77(3):491-8. doi: 10.1016/s0015-0282(01)03229-0. PMID: 11872201.

34. Chvapil M. New aspects in the biological role of zinc: a stabilizer of macromolecules and biological membranes. Life Sci. 1973 Oct 16;13(8):1041-9. doi: 10.1016/0024-3205(73)90372-x. PMID: 4202734.

35. Madding C, I, Jacob M, Ramsay V, P, Sokol R, Z: Serum and Semen Zinc Levels in Normozoospermic and Oligozoospermic Men. Ann Nutr Metab 1986;30:213-218. doi: 10.1159/000177196

36. Kothari RP, Chaudhari AR. Zinc Levels in Seminal Fluid in Infertile Males and its Relation with Serum Free Testosterone. J Clin Diagn Res. 2016 May;10(5):CC05-8. doi: 10.7860/JCDR/2016/14393.7723. Epub 2016 May 1. PMID: 27437207; PMCID: PMC4948382.

37. Zhao J, Dong X, Hu X, Long Z, Wang L, Liu Q, et al. Zinc levels in seminal plasma and their correlation with male infertility: A systematic review and. Nat Publ Gr [Internet]. 2016;(March):110. Available from: http://dx.doi.org/10.1038/srep22386 